\title{
The impacts of oral health-related quality of life of elderly people living at home: a cross-sectional study
}

\author{
Impactos da qualidade de vida relacionada à saúde bucal de idosos \\ em domicílio: estudo transversal
}

Roosevelt Silva Bastos (https://orcid.org/0000-0001-5051-1210) ${ }^{1}$

José Roberto Pereira Lauris (https://orcid.org/0000-0003-3475-4479) ${ }^{1}$

José Roberto Magalhães Bastos (https://orcid.org/0000-0003-4033-5043) ${ }^{1}$

Sofia Rafaela Maito Velasco (https://orcid.org/0000-0002-4323-0848) ${ }^{1}$

Debora Foger-Teixera (https://orcid.org/0000-0002-2187-3033) ${ }^{1}$

Leticia Marques Sá (https://orcid.org/0000-0003-3377-7783) ${ }^{1}$

${ }^{1}$ Faculdade de Odontologia de Bauru, Universidade de São Paulo. Alameda Otavio Pinheiro Brisola $9 / 75$, Vila Universitária. 17012-901

Bauru SP Brasil.

rtbastos@usp.br

\begin{abstract}
The scope was to verify the impact of oral and sociodemographic conditions, the dental treatment needs and dental pain, on the quality of life of the elderly. This cross-sectional study was conducted in 15 primary health care areas. A backward multivariate linear regression model was used $(p<0.05)$ with oral health related-quality of life as dependent variable. There were 335 elderly people with predominance of women (56.72\%) and aged up to 74 years (59.40\%). Those who had up to 8 years of education predominated (87.46\%), and those who were still working were the minority (13.43\%). Multivariate linear regression $(p<0.05)$ showed association with missing teeth $(\beta=0,12$; IC $0,00: 0,04 ; p<0,04)$ and dental prosthesis needs $(\beta=0,14 ;$ IC $0,13: 0,81$; $p<0,01)$, women $(\beta=0,18 ;$ IC $0,23: 0,85 ; p<0,01)$, less aged $(\beta=-0,12$; IC $-0,05: 0,00 ; p<0,02)$, not working ( $\beta=-0,15$; IC -1,09:-0,20; $p<0,01)$, with dental care need $(\beta=0,24 ;$ IC $0,25: 0,63 ; p<0,01)$ and dental pain $(\beta=0,14 ;$ IC $0,10: 0,64 ; p<0,01)$. Missing teeth, sociodemographic conditions, dental treatment needs and dental pain might impact oral health-related quality of life of elders.
\end{abstract}

Key words Aged, Aged 80 and over, Tooth loss, Quality of life, Public health
Resumo O objetivo foi verificar o impacto da condição bucal e sociodemográfica, necessidade de tratamento odontológico e dor dentária na qualidade de vida de idosos. Este estudo transversal realizou-se em 15 áreas de cuidados primários de saúde. O modelo de regressão linear multivariado foi utilizado $(p<0,05)$ considerando qualidade de vida como variável dependente. Participaram 335 idosos, predominio de mulheres (56,72\%) com idade até 74 anos (59,40\%). Ter até 8 anos de estudo predominou $(87,46 \%)$ e os que trabalhavam eram minoria (13,43\%). A regressão linear multivariada $(p<0,05)$ apresentou associação da qualidade de vida com dentes perdidos $(\beta=0,12$; IC 0,00:0,04; $p<0,04)$ e necessidade de próteses ( $\beta=0,14$; IC 0,13:0,81; $p<0,01)$, com mulheres $(\beta=0,18 ;$ IC $0,23: 0,85 ; p<0,01)$, idosos mais jovens $(\beta=-0,12$; IC $-0,05: 0,00 ; p<0,02)$, que não trabalham $(\beta=-0,15 ;$ IC $-1,09:-0,20 ; \quad p<0,01)$, com necessidades de tratamento odontológico $(\beta=0,24 ;$ IC 0,25:0,63; $p<0,01)$ e dor dentária $(\beta=0,14 ;$ IC $0,10: 0,64 ; p<0,01)$. Dentes perdidos, aspectos sociodemográficos, necessidade de tratamento odontológico e dor dentária podem impactar a qualidade de vida relacionada à saúde bucal de idosos.

Palavras-chave Idoso, Idoso de 80 anos ou mais, Perda de dente, Qualidade de vida, Saúde pública 


\section{Introduction}

The last few decades were marked by a profound change in the demographic profile in Brazil ${ }^{1}$, and in other countries ${ }^{2}$, by the growth of the elderly population group. In addition to the difficulties inherent to age, because of coping with various risks throughout life, elderly persons usually present a great oral health burden, such as extensive tooth loss, and the few remaining teeth often present dental caries, manifested in crown and / or root, periodontal disease, without counting the needs related to oral rehabilitation.

Dental caries, periodontal disease, edentulism, dry mouth and pre-cancer / cancer lesions are the dental and oral conditions most frequently observed in the elderly ${ }^{3}$. These normative conditions have been discussed in the previously published literature, specially the importance of tooth loss and the oral health rehabilitation needs associated ${ }^{3-10}$. In recent years the relationship between these conditions was added to its perception, known as oral health-related quality of life. In the elderly, this topic has been investigated by the Oral Health Impact Profile (OHIP) questionnaire ${ }^{11}$, most often in its reduced version $(\text { OHIP-14 })^{12}$ that has been validated for Portuguese in Brazil ${ }^{13}$. This instrument is also used in other age groups and to evaluate clinical conditions ${ }^{14,15}$. OHIP-14 presents seven dimensions (functional limitation, physical pain, psychological discomfort, physical disability, psychological disability, social disability and handicap) with two issues related to each dimension. Initially, the studies presented their conclusions based on the mean scores of the impacts observed, however, later the prevalence, severity, and especially the extent of impacts were used to report the results of the studies ${ }^{16}$, in an adequate theoretical framework ${ }^{17}$. The severity is related to the OHIP14 mean results, therefore resulting in the general impact investigated. The extent variable reveals the OHIP-14 mean only of those considered with impact.

The impact of the normative dental condition on oral health-related quality of life (OHRQoL) of the elderly has previously been investigated, usually focused on an isolated condition or few together. The need for dental prosthesis was found to be significantly associated with a negative impact on oral health-related quality of life; also significant were dental pain and lack of satisfaction with oral health ${ }^{18}$. The positive predictors were: satisfaction with the use of prosthesis, for rehabilitation treatment ${ }^{19}$, and a higher family income for oral health-related quality of life ${ }^{18}$. Nevertheless, few studies have related the impact of the main oral conditions of the elderly relative to their severity and extent on the oral health-related quality of life of this population, other than the World Health Organization (WHO) recommendation for epidemiological surveys for older people (65-74 years) in Brazil $^{20}$.

Thus, the objective of this cross-sectional study was to verify the impact of clinical (normative) dental variables (missing teeth; filled teeth; dental caries; clinical attachment loss; oral mucosal lesions, and dental prosthesis use / need); sociodemographic conditions (sex, age - in years, occupation and school - in years); the dental care need and self-reported of dental pain, on the severity and extent of the oral health related-quality of life of elderly people.

\section{Material and methods}

The city of Bauru, ranked $37^{\text {th }}$ among Brazilian cities with a Human Development Index (IDH-M=0,801), is in the central region of the state of São Paulo. In 2010, it had 343,937 inhabitants, of whom $23,633(6,87 \%)$ were aged between 60 and 69 years, and 21,147 (6,15\%) people of 70 years of age, or older. The predominance of females increased with age, with 56.01\% and $60,52 \%$, respectively ${ }^{21}$. The public health network in primary health care is composed by 25 Health Clinics (HC) for $10,41 \%$ of oral health coverage population ${ }^{22}$. This cross-sectional study report was made in compliance with the recommendations of the Strengthening the Reporting of Observational Studies in Epidemiology (Strobe Guidelines).

\section{Sample assessment and calibration process}

The two examiners discussed the clinical variables prior to the pilot study with pictures. Then, five dentate and five edentulous elderly volunteers (65-74 years of age) were examined for each clinical variable at Vila Dutra Public Health Clinic in two different moments, in two days. The last round of exams was satisfactory for intra and inter-examiner Kappa statistics (Kappa $>0,80$ ). Only mucosal lesions were not observed in those elderly volunteers therefore it wasn't registered.

The population enrolled in the Vila Dutra Public Health Clinic participated in a pilot study to observe the data collection methodology, instruments used, and the time spent on collec- 
tion. The pilot study lasted for six periods of 4 hours, to enable 35 participants to be examined and respond to the questionnaires twice, with a two-week interval between them. Inter-examiner and intra-examiner Kappa statistics were satisfactory for all variables related to the oral condition satisfactorily, and for the OHIP-14 instrument (Kappa $>0.80$ ). We performed the sample calculation for each oral condition investigated and for oral health-related quality of life (OHIP-14). The largest sample calculated among clinical (normative) dental variables and OHIP14 was the dental prosthesis use $(68,57 \%)$, hence with a minimum need of 341 elderly in the study to represent the elderly population coverade by Oral Health Primary Health Attention in Bauru in 2015. The estimated sample was based on a finite population (4941), with a 5\% error, 95\% confidence level and a design effect of 1.1. This design effect is proposed because there is no public information by age groups for the neighborhoods or any regions from Bauru, nevertheless $10 \%$ was added to the calculus to let the final sample the most reliable as possible. Oral health coverage at Bauru for Primary Health Attention (37910 inhabitants) and the people older than 64 years $(13,02 \%$ at Bauru) was considered for sampling process. This paper describes a study with other results not included here, and in the main methodology it was decided to include conveniently the Family Health Units. The city was divided into central, northern, southern, eastern and western regions. Despite the distribution of Health Clinics over the city is not equal it was decided to select three HC per region by means of lottery to represent Bauru elderly home population equally, therefore totaling fifteen subpopulations $(15 \mathrm{HC})$ distributed throughout the city (figure 1), with exception for the western and northern regions which The Family Health Clinics were all conveniently selected. This estimated sample was considered to represent the people with 65 years old or more from the coverage area of Primary Oral Health Attention from Bauru, Brazil.

The target sampling (341) was divided by the fifteen $\mathrm{HC}$ regions stablished in the study for the city of Bauru, thus with 23 blocks for each region (Figure 1). All the blocks of the coverage area of each public health unit was numbered. Then, by simple sampling, 23 blocks (one block per senior citizen) were randomly selected. In each block, the research group began the journey walking through the left corner of the north face of the block, always working in a clockwise direction, to enroll the individuals of the elderly age group with the aim to reach one participant by block. The first elderly person localized was invited to participate, and in the cases with more than one elder person in the house every one was invited to participate. Elderly persons 65 or more years old were selected, and only those who showed cognitive difficulties with understanding and answering the questions were excluded, nevertheless no instrument targeting cognitive condition was used.

All epidemiological examinations for oral conditions were performed in a room with adequate light, with the participant and examiner sitting opposite each other. A flat mirror (SSWhite Duflex, São Paulo) and CPI probe (Trinity, lot L0561C, São Paulo) were used, and before the exams dental brushing was performed by the volunteers.

\section{Independent variables}

The indices used were Decayed/Missing/ Filled/Teeth (DMFT), Clinical Attachment Loss (CAL), Oral Mucosal Lesions ${ }^{20}$ and Dental Prosthesis Use / $\mathrm{Need}^{23}$. The oral condition of the elderly was represented in this study by the following independent variables derived from the indices cited in the previous paragraph: sound teeth, missing teeth (any reason), filled teeth, dental caries (crown or root), Clinical Attachment Loss, oral mucosal lesions, dental prosthesis (use / no use; need / no need).

The socio-demographic variables were collected by interview and included sex (male or female), skin color (not white or white), age (in years from 65), occupation (does not work, or work) and formal schooling (school - in years of formal education). The elderly was asked about dental care need (no or yes), and if they felt dental pain in the last 6 months (no or yes).

\section{Oral health-related quality of life (OHRQoL)}

To assess the oral health-related quality of life, the OHIP-14 instrument was used by interview, based on the last six months of the time of data collection ${ }^{13}$. The possible responses were Never (0), Hardly ever (1), Occasionally (2), Fairly often (3) and Very often (4), and the sum of the score of each question resulted in a variation from zero to 56 (Severity). The highest impact responses, Fairly often (3) and Very often (4) were summed per individual and corresponded to the dependent variable OHIP-14 Extension, hence to 
the effectively answers related to negative impact in quality of life. This sum corresponded to how many times each participant answered Fairly often (3) or Very often (4) for each of the fourteen questions of OHIP-14, hence ranging from zero to fourteen.

\section{Statistical analysis}

The bivariate analysis performed was the Simple Regression Analysis between both dependent variables and all the independent variables $(\mathrm{p}<0.05)$. Two multivariate linear regressions were performed with the severity and extent of the OHIP-14 instrument as dependent variables. The first time, all the independent variables were included, in the second, only the variables that presented value of $\mathrm{p}<0.20$, characterizing two backward stepwise multivariate linear regressions.

In both cases, OHIP-14 severity and OHIP-14 extension, we analyzed the assumptions of multivariate linear regressions by assessing the residuals of the independent variables. The linearity of the parameters was evaluated by the correlation coefficient. The homocedasticity, characterized by the constant variance of residues, was evaluated by the Pesarán-Pesarán Test. The Durbin Watson test (DW Test) was used to evaluate the independence of the terms (null covariance). Normality of the residual's distribution was assessed by the Kolmogorov-Smirnov test. The collinearity was evaluated by the analysis of the tolerance value and the Variance Inflation Factor (the values accepted are Tolerance greater than 0.10 and VIF less than 10.00$)^{24,25}$.

\section{Ethical aspects}

This study was approved and conducted in compliance with the requirements and recommendations of Brazilian Law.

\section{Results}

From the surrounding 15 public health clinics, there were 338 persons eligible by age, but 3 were excluded because of cognitive difficulties of understanding and expression. The refusals were not registered and there was three losts. Data about the studied population is presented in Table 1 , and it is related to the mean severity and extension of the OHIP-14 instrument. There was a predominance of females $(56,72 \%)$, and age group between 65 and 74 years (59,40\%), with a total range from 65 to 101 years of age. The elderly with up to eight years of formal schooling reported $(87,46 \%)$, and not working elders $(86,57 \%)$ predominated.

The results of the OHIP-14 instrument are presented in Table 2, with the prevalence, mean values of severity and extent of impact. For internal reliability, the Cronbach's alpha value for OHIP-14 $(0,77)$ was calculated. The severity shown in the OHIP-14 instrument was higher, mainly in the dimension of physical pain related to unconfortable to eat, followed by psychological discomfort (self-conscious) and psychological disability (embarrassed) and then by functional limitation (pronounce and taste). The extent of negative impacts was higher in the physical pain dimension (unconfortable to eat), followed by psychological discomfort (self-concious), psychological disability (embarrassed), functional limitation (taste).

The simple linear regressions between OHIP14 severity and extension is presented at Table 3. In both analysis the statiscally significant results $(p<0,05)$ are related to the elders with normative dental prosthesis need, females, less age, to be not working, and to the perception of dental care need and dental pain.

The multivariate linear regression (Table 4) between the dependent variable severity of the negative impacts of the OHIP-14 instrument is presented in in two stages. In the first, all independent variables were included in the model. In the second stage, the model was assembled with variables with $\mathrm{p}$ value equal to or less than 0.20 . The only oral condition associated with OHIP14 severity in second stage was dental prosthesis need, and the socio-demographic variables associated were female sex, the not working elder person (occupation), the dental care need and dental pain. This model explained $24,00 \%\left(\mathrm{R}^{2}\right)$ of the OHIP-14 severity variability $(\mathrm{p}<0,001)$.

The extent of the negative impacts of OHIP14 was the dependent variable shown in the multivariate linear backward analysis presented in Table 4, with the same methodology by the variable OHIP-14 severity. In the last step, the oral condition associated variables with p-value less than 0.20 were missing teeth and dental prosthesis need, and the socio-demographic variables were elders with less age, female sex, the not working elder person (occupation), dental prosthesis need and dental pain. This model explained $18,00 \%$ of the OHIP- 14 extent variability $(p<0,001)$. 
Table 1, Distribution of OHIP-14 severity and extension by independent variables, Bauru, São Paulo State, Brazil, 2015,

\begin{tabular}{|c|c|c|c|c|c|c|c|}
\hline & & & & OHIP- & Severity & OHIP-1 & Extension \\
\hline & & $\mathbf{n}$ & $\%$ & Mean & $\begin{array}{l}\text { Standard } \\
\text { Deviation }\end{array}$ & Mean & $\begin{array}{l}\text { Standard } \\
\text { Deviation }\end{array}$ \\
\hline Sound teeth & zero & 210 & 62,69 & 6,45 & 7,22 & 1,00 & 1,57 \\
\hline & $01-10$ & 89 & 26,57 & 6,85 & 7,11 & 0,99 & 1,50 \\
\hline & 11 or more & 36 & 10,75 & 5,14 & 0,67 & 0,67 & 1,29 \\
\hline Missing teeth & zero & 1 & 0,3 & 2,00 & 0,00 & - & - \\
\hline & $01-10$ & 26 & 7,76 & 6,69 & 6,20 & 0,92 & 1,32 \\
\hline & 11 or more & 308 & 91,94 & 6,41 & 7,13 & 0,97 & 1,54 \\
\hline Filled teeth & zero & 254 & 75,82 & 6,41 & 7,18 & 0,98 & 1,56 \\
\hline & $01-10$ & 71 & 21,19 & 6,52 & 6,74 & 0,94 & 1,45 \\
\hline & 11 or more & 10 & 2,99 & 5,70 & 6,43 & 0,70 & 1,25 \\
\hline Dental caries & zero & 253 & 75,52 & 5,84 & 6,62 & 0,88 & 1,44 \\
\hline & $01-10$ & 80 & 23,88 & 8,36 & 8,05 & 1,25 & 1,75 \\
\hline & 11 or more & 2 & 0,6 & 1,50 & 2,12 & - & - \\
\hline Clinical attachment loss & No & 204 & 60,90 & 6,11 & 6,75 & 0,94 & 1,49 \\
\hline & Present & 131 & 31,10 & 6,94 & 7,48 & 1,01 & 1,58 \\
\hline Oral mucosal lesion & No & 257 & 76,72 & 6,29 & 6,90 & 0,91 & 1,47 \\
\hline & Present & 78 & 23,28 & 6,91 & 7,50 & 1,13 & 1,69 \\
\hline Dental prosthesis use & No use & 76 & 22,69 & 7,01 & 6,28 & 1,01 & 1,35 \\
\hline & 1 or more & 259 & 77,31 & 6,27 & 7,25 & 0,95 & 1,57 \\
\hline Dental prosthesis need & No need & 101 & 30,15 & 4,54 & 6,43 & 0,52 & 1,29 \\
\hline & Need & 234 & 69,85 & 7,25 & 7,15 & 1,15 & 1,58 \\
\hline Sex & Male & 145 & 43,28 & 5,20 & 6,14 & 0,70 & 1,31 \\
\hline & Female & 190 & 56,72 & 7,38 & 7,54 & 1,16 & 1,65 \\
\hline Age (in years) & 65 a 74 & 199 & 59,40 & 7,26 & 7,84 & 1,16 & 1,75 \\
\hline & 75 or more & 136 & 40,60 & 5,23 & 5,48 & 0,68 & 1,05 \\
\hline Occupation & No work & 290 & 86,57 & 5,99 & 6,49 & 0,87 & 1,36 \\
\hline & Work & 45 & 13,43 & 9,33 & 9,46 & 1,56 & 2,23 \\
\hline School (in years) & $\leq 8$ years & 293 & 87,46 & 6,55 & 7,26 & 1,00 & 1,56 \\
\hline & $>8$ years & 42 & 12,54 & 5,62 & 5,28 & 0,69 & 1,20 \\
\hline Dental care need & Not affirmed & 173 & 51,64 & 3,39 & 4,33 & 0,40 & 0,97 \\
\hline & Affirmed & 162 & 48,36 & 9,49 & 7,86 & 1,53 & 1,76 \\
\hline Dental pain & Not affirmed & 276 & 83,69 & 5,18 & 5,67 & 0,75 & 1,22 \\
\hline & Affirmed & 58 & 17,31 & 12,18 & 9,73 & 1,98 & 2,27 \\
\hline Total & & 335 & 100,00 & 6,41 & 7,05 & 0,96 & 1,53 \\
\hline
\end{tabular}

Source: The authors.

Analysis of the residuals of the independent variables in both multivariate linear regressions demonstrated linearity of the parameters (OHIP-14 Severity $r=0,27, p<0,001 /$ OHIP-14 Extension $\mathrm{R}=0,15, \mathrm{p}<0,001)$, independence of terms (OHIP-14 Severity DW Test $=2,034$ and OHIP-14 Extension DW test $=2,064$, therefore acceptable result in both cases) ${ }^{24}$ and absence of collinearity (Tolerance $>0,10$ and VIF $<10,00$ ). However, there was no normality in the distribution of residues (OHIP-14 Severity KS $=0,076$, $\mathrm{p}=0,000$, OHIP-14 Extension $\mathrm{KS}=0,158, \mathrm{p}=$ $0,000)$ and analyzes showed heterocedasticity in the Pesarán-Pesarán Test ( $\mathrm{p}<0,000$; OHIP-14 Severity / $p<0,000$; OHIP-14 Extension). 
Table 2. The severity, extent and prevalence of negative impacts according to the OHIP-14 dimensions reported by the elderly. Bauru, Brazil, 2015.

\begin{tabular}{|c|c|c|c|c|c|}
\hline & \multirow{2}{*}{$\begin{array}{c}\text { Severity }^{\star} \\
\text { Average (sd) }\end{array}$} & \multirow{2}{*}{$\begin{array}{l}\text { Extention }^{\star *} \\
\text { Average (sd) }\end{array}$} & \multicolumn{2}{|c|}{ Prevalence $^{\star * *}$} & \multirow{2}{*}{$\begin{array}{c}\text { Cronbach } \\
\text { Alpha }\end{array}$} \\
\hline & & & $\mathbf{n}$ & $\%$ & \\
\hline \multicolumn{6}{|l|}{ Functional limitation } \\
\hline Pronounce & $0,60(1,14)$ & $0,07(0,26)$ & 25 & 7,46 & 0,70 \\
\hline Taste & $0,55(1,22)$ & $0,10(0,30)$ & 34 & 10,15 & 0,71 \\
\hline \multicolumn{6}{|l|}{ Physical pain } \\
\hline Painful aching & $0,53(1,01)$ & $0,05(0,23)$ & 18 & 5,37 & 0,71 \\
\hline Unconfortable to eat & $1,42(1,55)$ & $0,24(0,43)$ & 80 & 23,88 & 0,70 \\
\hline \multicolumn{6}{|l|}{ Psychological discomfort } \\
\hline Self-conscious & $1,01(1,49)$ & $0,18(0,39)$ & 62 & 18,51 & 0,69 \\
\hline Felt tense & $0,45(1,02)$ & $0,06(0,24)$ & 20 & 5,97 & 0,69 \\
\hline \multicolumn{6}{|l|}{ Physical disability } \\
\hline Diet & $0,42(0,96)$ & $0,05(0,23)$ & 18 & 5,37 & 0,70 \\
\hline Interrupt meals & $0,18(0,60)$ & $0,01(0,09)$ & 3 & 0,90 & 0,71 \\
\hline \multicolumn{6}{|l|}{ Psychological disability } \\
\hline Difficult to relax & $0,16(0,57)$ & $0,01(0,09)$ & 3 & 0,90 & 0,71 \\
\hline Embarrassed & $0,76(1,37)$ & $0,14(0,34)$ & 46 & 13,73 & 0,69 \\
\hline \multicolumn{6}{|l|}{ Social disability } \\
\hline Irritable & $0,10(0,47)$ & $0,01(0,08)$ & 2 & 0,60 & 0,71 \\
\hline Usual jobs & $0,04(0,36)$ & $0,01(0,08)$ & 2 & 0,60 & 0,72 \\
\hline \multicolumn{6}{|l|}{ Handicap } \\
\hline Less satisfying life & $0,11(0,59)$ & $0,02(0,14)$ & 7 & 2,09 & 0,70 \\
\hline Totally unable to function & $0,06(0,42)$ & $0,01(0,09)$ & 3 & 0,90 & 0,77 \\
\hline Total & $6,39(7,04)$ & $0,94(1,52)$ & 149 & 44,48 & 0,77 \\
\hline
\end{tabular}

${ }^{*}$ Values of OHIP-14.

${ }^{* *}$ Average answers for "fairly often" and "very often".

*** Number of participants and percentual who answered "fairly often" and "very often".

Source: The authors.

Table 3.Simple linear regression between OHIP-14 severity and extension with independent variables. Bauru, São Paulo State, Brazil. 2015.

\begin{tabular}{|c|c|c|c|c|c|c|c|c|}
\hline \multirow[b]{4}{*}{ Sound teeth } & \multicolumn{8}{|c|}{ OHIP-14 } \\
\hline & \multicolumn{4}{|c|}{ Severity } & \multicolumn{4}{|c|}{ Extension } \\
\hline & \multirow{2}{*}{\begin{tabular}{c|}
$\boldsymbol{\beta}$ \\
$-0,08$
\end{tabular}} & \multicolumn{2}{|c|}{$95 \% \mathrm{CI}$} & \multirow{2}{*}{$\begin{array}{c}\text { p-value } \\
0,16\end{array}$} & \multirow{2}{*}{$\begin{array}{c}\boldsymbol{\beta} \\
-0,05\end{array}$} & \multicolumn{2}{|c|}{$95 \% \mathrm{CI}$} & \multirow{2}{*}{$\frac{\text { p-value }}{0,36}$} \\
\hline & & $-0,05$ & 0,01 & & & $-0,21$ & 0,08 & \\
\hline Missing teeth & 0,03 & $-0,01$ & 0,03 & 0,59 & $-0,01$ & $-0,10$ & 0,09 & 0,89 \\
\hline Filled teeth & $-0,05$ & $-0,07$ & 0,03 & 0,40 & $-0,04$ & $-0,32$ & 0,16 & 0,52 \\
\hline Dental caries & 0,07 & $-0,03$ & 0,15 & 0,19 & 0,10 & $-0,04$ & 0,78 & 0,08 \\
\hline Clinical Attachment Loss & 0,02 & $-0,15$ & 0,23 & 0,71 & 0,03 & $-0,63$ & 1,13 & 0,58 \\
\hline Oral mucosal Lesion & 0,09 & $-0,05$ & 0,60 & 0,09 & 0,06 & $-0,63$ & 2,35 & 0,26 \\
\hline Dental prosthesis use & $-0,01$ & $-0,44$ & 0,34 & 0,80 & $-0,04$ & $-2,46$ & 1,14 & 0,47 \\
\hline Dental prosthesis need & 0,19 & 0,28 & 0,98 & 0,01 & 0,18 & 1,13 & 4,38 & 0,01 \\
\hline Sex & 0,15 & 0,14 & 0,79 & 0,01 & 0,16 & 0,70 & 3,73 & 0,01 \\
\hline Age (in years) & $-0,17$ & $-0,06$ & $-0,01$ & 0,01 & $-0,18$ & $-0,27$ & $-0,07$ & 0,01 \\
\hline Occupation & $-0,15$ & $-1,16$ & $-0,21$ & 0,01 & $-0,16$ & $-5,57$ & $-1,18$ & 0,01 \\
\hline School (in years) & $-0,03$ & $-0,20$ & 0,12 & 0,62 & $-0,02$ & $-0,85$ & 0,59 & 0,72 \\
\hline Dental care need & 0,29 & 0,34 & 0,72 & 0,01 & 0,35 & 2,09 & 3,82 & 0,01 \\
\hline Dental pain & 0,18 & 0,19 & 0,76 & 0,01 & 0,26 & 1,91 & 4,49 & 0,01 \\
\hline
\end{tabular}

Source: The authors. 
Table 4. Multivariate linear regression between the dependent variable Severity and Extention of OHIP-14 with the independent variables. Bauru, Brazil, 2015.

\begin{tabular}{|c|c|c|c|c|c|c|c|c|c|c|}
\hline & & \multirow[b]{2}{*}{$\beta$} & \multirow{2}{*}{\multicolumn{2}{|c|}{$95 \% \mathrm{CI}$}} & \multirow{2}{*}{$\begin{array}{c}\text { p- } \\
\text { value }\end{array}$} & \multicolumn{2}{|c|}{ Colinearity } & \multirow{2}{*}{$\mathbf{R}^{2}$} & \multirow{2}{*}{$\begin{array}{c}\mathrm{R}^{2} \\
\text { adjusted }\end{array}$} & \multirow{2}{*}{$\begin{array}{c}\text { p- } \\
\text { value }\end{array}$} \\
\hline & & & & & & Tolerance & VIF & & & \\
\hline & Constant & & $-1,49$ & 13,45 & 0,12 & & & 0,26 & 0,24 & $<0,001$ \\
\hline & Dental caries & 0,10 & $-0,04$ & 0,8 & 0,08 & 0,75 & 1,34 & & & \\
\hline & Missing teeth & 0,10 & $-0,01$ & 0,18 & 0,09 & 0,70 & 1,43 & & & \\
\hline \multirow[t]{10}{*}{ Severity } & $\begin{array}{l}\text { Dental prostesis } \\
\text { need }\end{array}$ & 0,12 & 0,36 & 3,37 & 0,02 & 0,93 & 1,08 & & & \\
\hline & Age (in years) & $-0,10$ & $-0,19$ & 0,00 & 0,05 & 0,90 & 1,11 & & & \\
\hline & Sex & 0,19 & 1,33 & 4,09 & 0,01 & 0,94 & 1,06 & & & \\
\hline & Occupation & $-0,15$ & $-4,99$ & $-1,01$ & 0,01 & 0,95 & 1,05 & & & \\
\hline & Dental care need & 0,30 & 1,70 & 3,38 & 0,01 & 0,91 & 1,09 & & & \\
\hline & Dental pain & 0,21 & 1,45 & 3,83 & 0,01 & 0,96 & 1,04 & & & \\
\hline & Constant & & $-0,45$ & 2,91 & 0,15 & & & 0,20 & 0,18 & $<0,001$ \\
\hline & Dental caries & 0,09 & $-0,02$ & 0,17 & 0,11 & 0,75 & 1,34 & & & \\
\hline & Missing teeth & 0,12 & 0,00 & 0,04 & 0,04 & 0,70 & 1,43 & & & \\
\hline & $\begin{array}{l}\text { Dental prostesis } \\
\text { need }\end{array}$ & 0,14 & 0,13 & 0,81 & 0,01 & 0,93 & 1,08 & & & \\
\hline \multirow[t]{5}{*}{ Extention } & Age (in years) & $-0,12$ & $-0,05$ & 0,00 & 0,02 & 0,90 & 1,11 & & & \\
\hline & Sex & 0,18 & 0,23 & 0,85 & 0,01 & 0,94 & 1,06 & & & \\
\hline & Occupation & $-0,15$ & $-1,09$ & $-0,20$ & 0,01 & 0,95 & 1,05 & & & \\
\hline & Dental care need & 0,24 & 0,25 & 0,63 & 0,01 & 0,91 & 1,09 & & & \\
\hline & Dental pain & 0,14 & 0,10 & 0,64 & 0,01 & 0,96 & 1,04 & & & \\
\hline
\end{tabular}

${ }^{*}$ Backward multivariate linear regression $(\mathrm{p}<0.20)$

Source: The authors.

\section{Discussion}

Oral health-related quality of life research in the elderly through extension assessment was more sensitive to highlight the impact of the independent variables observed, despite of the minor determination coefficient $\left(\mathrm{R}^{2}\right)$. It is reasonable to highlight that elders with less age and females were more sensitive to the negative impacts of oral health, also the not working elders. The perception of dental care need and dental pain also impacted both OHQoL impacts. The conditions related to tooth loss also showed negative impact in quality of life, for the missing teeth itself and dental prosthesis need.

The OHIP-14 severity carries the whole impact of a study, obviously related to a complete protocol in a quality of life investigation, nevertheless there is no cut point between impact and no impacted condition, therefore the higher determination coefficient $\left(R^{2}\right)$ does not surprise. An alternative to this methodologic discussion is the use of the extension concept, which highlight only the cases where the impact is effective, in this study represented by the answers "Fairly often" and "Very often". Despite the minor determination coefficient $\left(\mathrm{R}^{2}\right)$, which is related to a partial protocol, the sensitive aspect is important to reveal stronger relation of quality of life perception to the independent variables as missing teeth in this study. Hence the OHIP-extension is a good alternative to OHIP-severity in the investigation of oral health related quality of life.

Only OHIP-14 extension was associated with missing teeth reinforcing the results of previous studies $^{26}$. The indication of extracting the remaining teeth, and subsequently inserting dental prosthesis has been discussed, with the aim of ending a long period of dental pain. This would be a clinical and social decision ${ }^{(2)}$ which has declined considerably in some countries ${ }^{27}$. Missing teeth is a serious health care failure denoting a shared responsibility between poor selfcare and the health care system that has been unable to promote the maintenance of minimally functional dentition. Therefore, there is obvious need for missing teeth prevention throughout life.

People with missing teeth, especially those who are edentulous, make inadequate food choic$\mathrm{es}^{(28)}$; they may use inappropriate prosthesis and 
also have a negative impact on oral health-related quality of life. In this study, the highest negative impact observed among the dimensions of the OHIP-14 instrument was on chewing, followed by concern and feeling ashamed of teeth, mouth or dentures, suggesting that the elderly attached greater importance to function and esthetics, aspects strongly related to missing teeth and the need for oral rehabilitation.

Direct consequences of the lack of maintenance of dental prosthesis were ulcerated lesions observed, probably related to recurrent traumas of poorly adapted prosthesis and fungi due to inadequate hygiene of removable prosthesis ${ }^{4}$. In both cases, incipient lesions do not cause pain or disconfort sensation at the hard palate or other oral areas investigated, therefore the absence of association with its perception in this study was understandable.

Untreated dental caries might be perceived in children $^{29}$, adolescents ${ }^{14}$, and in older persons ${ }^{3}$, but in this study this disease was not perceived directly. The hypothesis we considered is that the remaining teeth of the elderly usually present dental caries in chronic stage, therefore associated to the tertiary dentine formed from the stimulus of dental caries to protect the pulp, minimizing the pain sensitivity. The impact of dental caries on the elderly has been evaluated before with DMFT $^{31}$, but this observed impact did not consider carious teeth without treatment alone, but added to the restored and missing teeth, which represents the larger part of the DMFT index in this age group because of the extensive missing teeth. Even though, public policies for treatment and to combat the incidence of tooth decay and root caries since adulthood ${ }^{6}$ should also be of concern to policy-makers to maintain tooth in elderly population, and in acceptable conditions.

The clinical attachment loss greater than 4 millimeters was not directly associated with OHIP-14 in this study, unlike the situation observed with data from SB Brazil Project $2010^{18}$, which used the Oral Impacts in Daily Performances (OIDP) instrument for the age group (65-74 years). In the elderly with a mean age of 67,02 years $(5,81)$, a Swedish study used the OHIP-14 instrument and observed a negative impact related to the need for complex periodontal treatment, and at an age of less than 70 years ${ }^{32}$. Periodontal disease in adults has been associated with a negative impact on oral health-related quality of life, and its treatment has a positive effect $^{33}$, but there are fewer studies with persons from the age of 75 and over, making it difficult to contextualize the reduction in the impact on function with advancing age $e^{34}$.

The concept that the elderly present a low negative impact on oral health-related quality of life because they have adapted themselves to the difficulties of their oral condition after many years of life was supported by our results ${ }^{34}$. The elderly over the age of 74 years presented diminished negative perception of oral health-related quality of life, despite their oral conditions represented by significant tooth loss, and remaining teeth (when present) with treatment needs such as dental caries, clinical attachment loss, and oral rehabilitation needs. The perception of pain of dental origin and the need for self-reported treatment corroborated the concept that oral health-related quality of life was mediated by the clinical condition, which in turn was influenced by sociodemographic determinants ${ }^{31}$, confirmed in our results by the variables age, sex and occupation.

The female sex presented an association with higher impact on oral health-related quality of life, corroborating an earlier study $y^{35}$. Female sensitivity relative to oral health needs is higher than it is in $\mathrm{men}^{36}$, they more frequently seek dental treatments, for example, making them more vulnerable to tooth loss. ${ }^{5}$. Thus, it was expected to find a higher negative impact on the elderly women.

Most of the elders wasn't working ${ }^{37}$, nevertheless occupation was an independent variable associated with the positive impact on oral health-related quality of life in the elderly. Nowadays, the elderly are increasingly engaged in work at home and even in formal jobs, socially justifying the investment in oral health care for the elderly, because with the improvement of their oral condition, elderly persons enjoy increased self-esteem and active social contact, contributing to the development of domestic labor activities or even employment ${ }^{38}$, it relates with the active aging.

Schooling is an important sociodemographic determinant and its association with oral health-related quality of life has been demonstrated in a previous study ${ }^{31}$, nevertheless this was not supported by our results.

In the multivariate regression model, there was no direct significance of dental caries, clinical attachment loss, and mucosal lesions, although all these questions presented high OHIP-14 values. Therefore, it was not surprising that the perception of dental pain $(17,31 \%)$ and the dental care need $(48,36 \%)$ were statistically significant in the multivariate regression model, since they harbored the perception of dental pain and the treat- 
ment needs that the elderly persons presented in their complex oral condition. Pain of dental origin is common among the elderly and increases with age, and the higher the number of teeth kept in the mouth ${ }^{39}$. Thus, the remaining teeth of the elderly usually present complex dental care needs at this stage of life ${ }^{40}$, which is a separate challenge to health managers.

The limitations of this study may be related to the cross-sectional design used, as it would be desirable for studies on oral health-related quality of life to be conducted with longitudinal model. However, the oral health condition and the social determinants of the elderly do not change much over the course of time; the important amplitude in the age-range from 65 to 101 years was outstanding, favoring this logic. Nevertheless, it is important to affirm that this was a cross-sectional research and the objectives of this study design were well satisfied. Another limitation would be to consider the external validity of the study compromised, because the research was carried out in a single municipality. However, for the survey conducted in Bauru (where the data from the study came from), a city in the interior of the state of São Paulo, the DMFT index was 28,79 $(5,53)$ and for the state of São Paulo ${ }^{(41)}$ not in the same year - it was $28.22(0,17)$. For these studies, similar values were also observed for other variables, such as, for example: "no need for maxillary dental prosthesis - 23,15\%" in the present study, and $24,21 \%$ for the State of São Paulo in 2015. Therefore, the present study presented good potential for generalization and reasonable acceptable results.

Other limitations might be considered as many individual and contextual determinants could be included at the model performed in this study, nevertheless it was not plenty collect- ed / included in this paper. Alcohol consumption and smoking habits may influence mucosal lesion prevalence as these behaviors are considered related to the incidence of pre-cancer/cancer lesions in vermillion zone of the lips and in oral mucosa ${ }^{3,42}$. Also, these behaviors might be associated to dental caries, periodontal disease and tooth loss. The use of medication might influence saliva production and quality contributing to the incidence of dental caries and periodontal disease and compromising the dental prosthesis stabili$\mathrm{ty}^{3}$. Hence, these conditions might also influence quality of life, nevertheless not part of this study.

In view of the increase in the elderly population and its important oral health needs, some actions should be taken, such as the inclusion of geriatric courses in dentistry undergraduate courses and strengthening of the public services in favor of health care of the elderly. Future studies should adress, preferably in prospective type, not only relating oral health condition to quality of life, but also relating research and satisfaction of dental care, cases in which there is loss of cognition, motor capacity and frailty, and with focus on educational and preventive programs targeting the elderly and their caregivers.

\section{Conclusions}

The negative impact diminished as the older persons aged, and females seemed to be more sensitive to this negative impact. Having an occupation at an older age suggested a positive impact, and the self-reported dental care need and dental pain showed negative impact. Therefore, these conclusions reinforce the need for oral health promotion throughout life cycles to favor oral health of the elderly.

\section{Collaborators}

RS Bastos contributed to the conception and design, acquisition, analysis, and drafted the manuscript. JRP Lauris and JRM Bastos critically revised the manuscript. SRM Velasco, D FogerTeixera and LM Sá contributed to the acquisition of data and critically revised the manuscript. All the authors gave the final approval. 


\section{Acknowledgements}

The authors thank the National Counsel of Technological and Scientific Development (Conselho Nacional de Desenvolvimento Científico e Tecnológico - CNPq) for the financial support, and each elderly person and their families for their contributions to the study.

\section{References}

1. Schmidt MI, Duncan BB, Azevedo e Silva G, Menezes AM, Monteiro CA, Barreto SM, Chor D. Menezes PR. Chronic non-communicable diseases in Brazil: burden and current challenges. Lancet 2011; 377(9781):1949-1961.

2. Woodward A, Blakely T. Nobody on the face of the globe lived longer. Lancet 2016; 387(10023):10491050.

3. Thomson WM. Epidemiology of oral health conditions in older people. Gerodontology 2014; 31(Supl.1):9-16.

4. Gheno JN, Martins MAT, Munerato MC, Hugo FN, Sant'Ana Filho M, Weissheimer C, Carrard VC, Martins MD. Oral mucosal lesions and their association with sociodemographic, behavioral, and health status factors. Braz Oral Res 2015; 29:0003.

5. Hugo FN, Hilgert JB, de Sousa MaL, da Silva DD, Pucca GA. Correlates of partial tooth loss and edentulism in the Brazilian elderly. Community Dent Oral Epidemiol 2007; 35(3):224-32.

6. Marques RA, Antunes JL, Sousa MLR, Peres MA, Frazão P. [Root caries prevalence and severity in Brazilian adults and older people]. Rev Saude Publica 2013; 47(Supl.3):59-68.

7. Azevedo MS, Correa MB, Azevedo JS, Demarco FF. Dental prosthesis use and/or need impacting the oral health-related quality of life in Brazilian adults and elders: results from a National Survey. J Dent 2015; 43(12):1436-1441.

8. Azevedo JS, Azevedo MS, Oliveira LJC, Correa MB, Demarco FF. [Needs for dental prosthesis and their use in elderly Brazilians according to the National Oral Health Survey (SBBrazil 2010): prevalence rates and associated factors]. Cad Saude Publica 2017; 33(8):e00054016.

9. Silva AE, Demarco FF, Feldens CA. Oral health-related quality of life and associated factors in Southern Brazilian elderly. Gerodontology 2015; 32(1):35-45.

10. Costa EH, Saintrain MV, Vieira AP. [Self-perception of oral health condition of the institutionalized and non institutionalized elders]. Cien Saude Colet 2010; 15(6): 2925-2930.

11. Slade GD, Spencer AJ. Development and evaluation of the Oral Health Impact Profile. Community Dent Health 1994; 11(1):3-11.

12. Slade GD. Derivation and validation of a short-form oral health impact profile. Community Dent Oral Epidemiol 1997; 25(4):284-290.

13. Oliveira BH, Nadanovsky P. Psychometric properties of the Brazilian version of the Oral Health Impact Profile-short form. Community Dent Oral Epidemiol 2005; 33(4):307-314.

14. Bastos RS, Carvalho ES, Xavier A, Caldana ML, Bastos JRM, Lauris JRP. Dental caries related to quality of life in two Brazilian adolescent groups: a cross-sectional randomised study. Int Dental J 2012; 62(3):137-143.

15. Tinoco-Araujo JE, Orti-Raduan ES, Santos D, Colturato VAR, Souza MP, Mauad MA, Saggioro TCM, Bastos RS, Silva Santos PS. Oral health-related quality of life before hematopoietic stem cell transplantation. Clin Oral Investig 2015; 19(9):2345-2349. 
16. Slade GD, Nuttall N, Sanders AE, Steele JG, Allen PF, Lahti S. Impacts of oral disorders in the United Kingdom and Australia. Br Dent J 2005; 198(8):489-493; discussion 483.

17. Tsakos G, Allen PF, Steele JG, Locker D. Interpreting oral health-related quality of life data. Community Dent Oral Epidemiol 2012; 40(3):193-200.

18. Prado RL, Saliba NA, Garbin CA, Moimaz SA. Oral impacts on the daily performance of Brazilians assessed using a sociodental approach: analyses of national data. Braz Oral Res 2015; 29:s1806.

19. Yen YY, Lee HE, Wu YM, Lan SJ, Wang WC, Du JK, Huang ST, Hsu KJ . Impact of removable dentures on oral health-related quality of life among elderly adults in Taiwan. BMC Oral Health 2015; 15:1.

20. World Health Organization (WHO). Oral health surveys: basic methods. $5^{\text {th }}$ ed. Geneva: WHO; 2013.

21. Instituto Brasileiro de Geografia e Estatística (IBGE) [Brazilian Institute of Geography and Statistics]. Censo 2010 [Internet]. Rio de Janeiro: IBGE; 2019 [acessado 2019 maio 08]. Disponível em: http://censo2010. ibge.gov.br/resultados.html.

22. Brasil. Ministério da Saúde (MS). [Brazilian Ministry of Health]. Cobertura da Atenção Básica [Internet]. Brasília: MS; 2019. [acessado 2019 maio 14]. Disponível em: https://egestorab.saude.gov.br/paginas/acessoPublico/relatorios/relHistoricoCoberturaAB.xhtml

23. World Health Organization (WHO). Oral health surveys: basic methods. $4^{\text {th }}$ ed. Geneva: ORH/EPID; 1997.

24. Corrar LJ, Paulo E, Dias Filho JM, Rodrigues A. Análise multivariada para os cursos de Administração, Ciências Contábeis e Economia. São Paulo: Atlas; 2017.

25. Marôco J. Análise estatística com o SPSS Statistics. Pêro Pinheiro (Portugal): Gráfica Manoel Barbosa \& Filhos; 2014

26. Gerritsen AE, Allen PF, Witter DJ, Bronkhorst EM, Creugers NHJ. Tooth loss and oral health-related quality of life: a systematic review and meta-analysis. Health Qual Life Outcomes 2010; 8:126.

27. Sussex PV. Edentulism from a New Zealand perspective - a review of the literature. $N Z$ Dent J 2008; 104(3):84-96.

28. Schimmel M, Katsoulis J, Genton L, Müller F. Masticatory function and nutrition in old age. Swiss Dent J 2015; 125(4):449-454.

29. Leal SC, Bronkhorst EM, Fan M, Frencken JE. Untreated cavitated dentine lesions: impact on children's quality of life. Caries Res 2012; 46(2):102-6.

30. Fejerskov O, Kidd E. Dental caries: the disease and its clinical management. $2^{\text {nd }}$ ed. UK: Blackwell Munksgaard; 2009.

31. Rebelo MA, Cardoso EM, Robinson PG, Vettore MV. Demographics, social position, dental status and oral health-related quality of life in community-dwelling older adults. Qual Life Res 2016; 25(7):1735-1742.

32. León S, Bravo-Cavicchioli D, Correa-Beltrán G, Giacaman RA. Validation of the Spanish version of the Oral Health Impact Profile (OHIP-14Sp) in elderly Chileans. BMC Oral Health 2014; 14:95.
33. Franke M, Bröseler F, Tietmann C. Patient-related evaluation after systematic periodontal therapy - a clinical study on periodontal health-related quality of life (PHQoL). Oral Health Prev Dent 2015; 13(2):1638.

34. Slade GD, Sanders AE. The paradox of better subjective oral health in older age. J Dent Res 2011; 90(11):1279-85.

35. Hewlett SA, Yawson AE, Calys-Tagoe BNL, Naidoo N, Martey P, Chatterji S, Kowal P , Mensah G, Minicuci N, Biritwum RB . Edentulism and quality of life among older Ghanaian adults. BMC Oral Health $2015 ; 15: 48$.

36. De Marchi RJ, Leal AF, Padilha DM, Brondani MA. Vulnerability and the psychosocial aspects of tooth loss in old age: a Southern Brazilian study. J Cross Cult Gerontol 2012; 27(3):239-358.

37. Milagres CS, Tôrres LHN, Neri AL, Sousa MLR. Self-perceived oral health status, chewing ability and longevity in the elderly. Cien Saude Colet 2018; 23(5):1495-1506.

38. Shtereva N. Aging and oral health related to quality of life in geriatric patients. Rejuvenation Res 2006; 9(2):355-357.

39. Kassebaum NJ, Bernabé E, Dahiya M, Bhandari B, Murray CJL, Marcenes W. Global Burden of Severe Tooth Loss: a systematic review and meta-analysis. $J$ Dent Res 2014; 93(Supl.7):20S-8S.

40. Murray CG. Advanced restorative dentistry - a problem for the elderly? An ethical dilemma. Aust Dent $J$ 2015;60(Supl.1):106-113.

41. Pereira AC, Vieira V, Frias AC. SB São Paulo 2015 Pesquisa estadual de saúde bucal: relatório final. Águas de São Pedro: Livronovo; 2016.

42. Porter S, Gueiros LA, Leão JC, Fedele S. Risk factors and etiopathogenesis of potentially premalignant oral epithelial lesions. Oral Surg Oral Med Oral Pathol Oral Radiol 2018; 125(6):603-611.

Article submitted 11/06/2018

Approved 08/06/2019

Final version submitted 10/06/2019

Chief Editors: Romeu Gomes, Antônio Augusto Moura da Silva 
